\title{
Using Actigraphy to Predict the Ecological Momentary Assessment of Mood, Fatigue, and Cognition in Older Adulthood: Mixed-Methods Study
}

Carolyn M Parsey ${ }^{1}, \mathrm{PhD}$; Maureen Schmitter-Edgecombe ${ }^{2}, \mathrm{PhD}$

${ }^{1}$ Department of Neurology, University of Washington School of Medicine, Seattle, WA, United States

${ }^{2}$ Department of Psychology, Washington State University, Pullman, WA, United States

Corresponding Author:

Carolyn M Parsey, $\mathrm{PhD}$

Department of Neurology

University of Washington School of Medicine

325 9th Avenue

Seattle, WA, 98104

United States

Phone: 12067443532

Email: cmparsey@uw.edu

\section{Abstract}

Background: Sleep quality has been associated with cognitive and mood outcomes in otherwise healthy older adults. However, most studies have evaluated sleep quality as aggregate and mean measures, rather than addressing the impact of previous night's sleep on next-day functioning.

Objective: This study aims to evaluate the ability of previous night's sleep parameters on self-reported mood, cognition, and fatigue to understand short-term impacts of sleep quality on next-day functioning.

Methods: In total, 73 cognitively healthy older adults (19 males, 54 females) completed 7 days of phone-based self-report questions, along with 24-hour actigraph data collection. We evaluated a model of previous night's sleep parameters as predictors of mood, fatigue, and perceived thinking abilities the following day.

Results: Previous night's sleep predicted fatigue in the morning and midday, as well as sleepiness or drowsiness in the morning; however, sleep measures did not predict subjective report of mood or perceived thinking abilities the following day.

Conclusions: This study suggests that objectively measured sleep quality from the previous night may not have a direct or substantial relationship with subjective reporting of cognition or mood the following day, despite frequent patient reports. Continued efforts to examine the relationship among cognition, sleep, and everyday functioning are encouraged.

(JMIR Aging 2019;2(1):e11331) doi: $\underline{10.2196 / 11331}$

\section{KEYWORDS}

actigraphy; aging; ecological momentary assessment; mood; sleep

\section{Introduction}

Recent trends in behavioral health have demonstrated the importance of quality sleep in older age [1]. However, nighttime sleep disturbances are common in older adults [2] such as early waking, poorer sleep efficiency (SE), and trouble falling asleep [3-5]. Sleep difficulties in cognitively healthy older adults have been associated with self-reports of poorer physical and mental functioning [6,7], indicating the importance of sleep in successful aging (ie, the preservation of physical and cognitive functioning and avoidance of disease processes [8].
Sleep complaints in older adults are also associated with cognitive and functional difficulties [9,10]. For example, poor sleep quality has been associated with poorer global cognitive functioning [11-13], as well as with specific deficits in memory $[14,15]$, attention, and executive functioning [16]. In addition, poorer overall health and increased daytime fatigue [17], as well as reduced participation in social and physical activities [18], have been attributed to poor sleep in the elderly. Although there is evidence that sleep problems increase in late-life, less is known about the specific sleep factors that contribute to both poorer cognitive and functional abilities. This study explored 
the impact of objectively measured sleep quality on self-reported measures of daily functioning (eg, mood, fatigue, and perceived cognitive functioning) in a community-dwelling older adult sample.

Ecological momentary assessment (EMA) allows the gathering of subjective measures multiple times per day [19,20]. EMA has been used extensively in research with physical activity monitoring [21,22] and to document affective changes [23,24]. A major advantage of EMA is capturing data in short timeframes, resulting in less bias from autobiographical memory strategies $[25,26]$. In addition, data collection occurs in the participants' natural environment without drastically changing or influencing their daily routine [27].

Given the variability in daily experiences, EMA approaches appear ideal for the assessment of fatigue, physical activity, and fluctuations in mood during the day. Furthermore, nightly comparisons may reveal more useful information relative to aggregated or averaged data, as night-to-night variability has been associated with greater sleep complaints in the elderly [28]. Lemola et al [29] found that greater variability in the total sleep time (TST) was associated with self-report of poorer sleep quality and subjective well-being; however, average sleep duration, sleep onset latency (SOL), and wake after sleep onset (WASO) were not related to self-reported well-being. McCrae et al [30] found that lower self-reported sleep quality was associated with more negative affect, but these relationships did not achieve significance for objective sleep measures. Russell et al [31] evaluated sleep measurements as predictors of next-day fatigue in patients with chronic fatigue syndrome and found that subjective, but not objective, sleep measures predict next-day fatigue. Furthermore, they found that negative mood in the morning mediated the effect between subjective sleep and fatigue.

This exploratory study tested a model of objective sleep measures as predictors of self-report measures of cognition, mood, and fatigue at 4 time blocks the following day (ie, morning, midday, afternoon, and evening). We hypothesized that greater SOL, poorer SE, and increased WASO from the previous night would predict EMA-based reports of more negative mood, greater daytime fatigue and sleepiness or drowsiness, and poorer perceived thinking abilities the following day. These relationships were expected to be strongest in the morning and midday time blocks because of their proximity to the previous night's sleep. In other words, if sleep quality impacts mood, cognition, or fatigue the following day, the influence would be greatest at times closest to the morning wake time (eg, feeling groggy or perception of less cognitive clarity in the morning) and prior to activities that could improve energy levels, mood, and cognition (eg, caffeine and exercise).

\section{Methods}

\section{Participants}

Participants aged $\geq 55$ years were recruited from the community (eg, newspaper ads and health fairs) and completed phone interview screenings including a brief medical review, the telephone interview for cognitive status (TICS) [32], and the Modified Clinical Dementia Rating [33]. Participants were excluded from the study if they obtained a TICS score of $\leq 27$ (the equivalent of a Mini-Mental State Examination of 24) [32] and a Modified Clinical Dementia Rating score $>0$, which would indicate cognitive impairment. Individuals with diagnosed sleep disorders (eg, chronic insomnia and sleep apnea) and current use of sleep medications or aids (eg, zolpidem and doxepin) were also excluded. Self-report of minor sleep complaints (eg, occasional difficulty falling asleep, staying asleep, or waking too early) were not considered exclusionary criteria, as these subthreshold sleep complaints are common in older adults and reflect normal sleep in a cognitively healthy population $[3,4]$. In addition, participants were screened for depression and excluded if they scored $>10$ on the Geriatric Depression Scale-Short Form [34], as well as other cognitive domains, including attention, verbal memory, language, and executive functioning (Table 1), to determine a cognitively healthy participant group.

In this study, 73 cognitively healthy older adults met the study criteria with, at least, 6 nights of actigraph data and $<75 \%$ of EMA questions answered. The 73 participants (19 males, 54 females) had a mean age of 67.64 (SD 9.59) years. Table 1 provides the descriptive data of the sample. This study was part of a larger longitudinal study on cognition and aging; as such, all participants completed a 3-hour battery of cognitive tests and questionnaires; scores were compared with normative data, and participants whose scores fell $\geq 1.5$ SDs below the mean were excluded from the sample (see Table 1 for average cognitive performances of the sample). After completing cognitive testing, participants wore an actigraph for 1 week while also completing EMA measures (ie, phone-based questions 4 times daily).

This study was approved for human subjects by the Washington State University Institutional Review Board under a study entitled "Activities of Daily Living, Executive Functioning and Aging" (Institutional Review Board Number 12606-011).

\section{Sleep Measures}

\section{Actigraph}

Mini-Motionlogger actigraphs (Ambulatory Monitoring Inc.) were worn on the nondominant wrist for 1 week of consecutive nights. Actigraph data were collected in Proportional Integration Mode, aggregated in 60-second epochs, and analyzed using the University of California, San Diego sleep scoring algorithm [35].

The following sleep variables were used for statistical analyses:

- SOL: Time elapsed from the start of the "down" interval of nighttime sleep until the first minute scored as sleep or inactive.

- SE: Percentage of minutes scored as "sleep" within the "down" interval.

- WASO: Total minutes scored as "wake" during the "down" interval after actigraphically determined sleep onset. 
Table 1. Demographic data and mean summary data for older adult participants.

\begin{tabular}{|c|c|c|}
\hline Variable or test & $\operatorname{Mean}^{\mathrm{a}}(\mathrm{SD})$ & Normative descriptor \\
\hline \multicolumn{3}{|l|}{ Demographics } \\
\hline Age & $67.64(9.59)$ & $\mathrm{N} / \mathrm{A}^{\mathrm{b}}$ \\
\hline Education (years) & $16.41(2.70)$ & N/A \\
\hline Gender & N/A & 19 male, 54 female \\
\hline \multicolumn{3}{|l|}{ Verbal ability and global status } \\
\hline Wechsler Test of Adult Reading total score & $44.34(3.61)$ & High average \\
\hline Telephone Interview for Cognitive Status total score & $35.30(2.04)$ & Nonimpaired \\
\hline \multicolumn{3}{|l|}{ Attention and speeded processing } \\
\hline Symbol Digit Modalities Test Oral total & $55.43(11.84)$ & High average \\
\hline \multicolumn{3}{|l|}{ Verbal memory } \\
\hline Memory Assessment Scale List Delayed Recall & $11.25(1.18)$ & Average \\
\hline \multicolumn{3}{|l|}{ Word finding and language } \\
\hline Boston Naming Test total correct & $57.23(2.96)$ & High average \\
\hline \multicolumn{3}{|l|}{ Executive functioning } \\
\hline D-KEFS ${ }^{\mathrm{C}}$ Letter Fluency & $41.90(11.84)$ & Average \\
\hline D-KEFS Design Fluency & $26.62(7.04)$ & Average \\
\hline Frontal Assessment Battery total & $16.83(1.68)$ & Nonimpaired \\
\hline
\end{tabular}

${ }^{\mathrm{a}}$ Unless otherwise indicated, mean scores are raw scores.

${ }^{b}$ N/A: not applicable.

${ }^{\mathrm{c} D}$-KEFS: Delis-Kaplan Executive Functioning System.

Textbox 1. Ecological momentary assessment phone questions and response options.

"Your general thinking abilities are currently..."

- $\quad$ Response options: Very Good, Good, Fair, Poor, Very Poor (1-5, respectively)

"Your general mood is currently..."

- $\quad$ Response options: Very Good, Good, Fair, Poor, Very Poor (1-5, respectively)

"How fatigued do you feel currently?"

- $\quad$ Response options: Not at all or none, A Little Bit, Somewhat, Quite a Bit, Very Much (1-5, respectively)

"In the past 2 hours, how sleepy or drowsy have you felt?"

- $\quad$ Response options: Not at all or none, A Little Bit, Somewhat, Quite a Bit, Very Much (1-5, respectively)

\section{Ecological Momentary Assessment}

EMA self-report measures of mood, fatigue, sleepiness or drowsiness, and perceived thinking were obtained using an automated phone system for 7 consecutive days (corresponding to actigraph data collection). Each day was divided into 4 time blocks as follows: morning (9:30-11:30 am); midday (12:30-2:30 pm); afternoon (3:30-5:30 pm); and evening (6:30-8:30 pm). Participants received an automated call at a random time during each time block. If they did not answer the phone, the system automatically redialed 10 minutes later (up to 2 redials within each block). The same 4 questions were asked at each time block, including the current assessment of mood, fatigue, drowsiness, and thinking abilities (Textbox 1). Questions included a 2-hour time window, "In the past 2 hours...," to capture the time elapsed within the 2-hour time block. Participants used the numeric phone keypad to respond to questions using Likert-style continuums (eg, "For 'Very Good', press 1").

The average TST for the sample was 413.69 (SD 76.60) minutes, which equates to roughly 6.89 hours of sleep per night. However, Spearman correlations revealed that the TST and the EMA question of daily activity completion did not demonstrate correlations with any other variable (ie, correlations >.200); thus, actigraphic TST and EMA completion of daily activities were not included in regression analyses. For 
comprehensiveness, when ordinal logistic regression (LR) models were run with and without TST, the presence of TST did not influence the outcome of the model. To increase the power of the ordinal logistic regression models, as well as eliminate predictor variables that did not demonstrate preexisting relationships with dependent variables, the TST was not included as a predictor of the EMA data in the regression models.

All variables were evaluated for normality prior to conducting statistical analyses. Although the EMA data were skewed, the transformation of the EMA data would make it difficult to interpret findings of the ordinal logistic regression models. Rather than using transformation techniques, and to preserve the ordinal nature of the EMA data, statistical procedures were selected depending on the data type. Spearman correlations $(\rho)$ were conducted for rank-order correlations that did not assume a normal distribution (eg, EMA questions), while Pearson correlations $(r)$ were conducted for actigraph data, which were normally distributed. Initial correlations were conducted to identify relationships between EMA and actigraph data. Then, a within-subjects ordinal logistic regression model was run using the variables that surfaced as having significant relationships with the dependent measure (per findings of Spearman correlations at $P<.01$ ); this model evaluated the influence of previous night's sleep measures on the EMA data the following day.

Ordinal logistic regression models were run individually for the prediction of the EMA data at each time block. Participants' age was held constant in all models. Measures of SOL, SE, and WASO from the previous night's sleep were entered simultaneously as predictors of EMA self-reports of mood, fatigue, sleepiness or drowsiness, and perceived thinking abilities at morning, midday, afternoon, and evening time blocks the following day. Significance values for model fit were set at $P<.01$.

\section{Results}

\section{Actigraph Sleep Data}

Participants wore actigraphs for an average of 7.47 nights (SD 0.40). Measures of SE (mean 91.93\% [SD 5.02]), SOL (mean 20.30 [SD 16.23] minutes), and WASO (mean 38.10 [SD 28.34] minutes) were consistent with cognitively healthy older adult samples in other studies [36]. Longer SOL $(r=-.361, P=.002)$, but not SE and WASO ( $r=-.096$ to.020, $P=.002$ ), correlated with older age. Table 2 presents actigraph data for the participant sample.

\section{Ecological Momentary Assessment Data}

On average, participants completed EMA questions for 7.96 (SD 0.44) days and answered an average of $79.52 \%$ morning, $75.35 \%$ midday, $81.49 \%$ afternoon, and $83.03 \%$ evening phone calls. Older age exhibited small correlations with EMA reports of greater sleepiness or drowsiness at the morning time block ( $\rho=-.265, P=.03$ ) and more negative mood at the morning time block $(\rho=-.238, P=.04)$. Figure 1 shows the mean values of the EMA data.

\section{Spearman Correlations}

Correlations of evening EMA data (Day A, Time 4) with the EMA data the following day (Day B, Times 1-4) revealed that prior evening self-reports of mood, fatigue, sleepiness or drowsiness, and perceived thinking abilities generally correlated with EMA reports for identical questions the next morning, midday, afternoon, and evening $(\rho=.389-.747, P=.002-.001$; Table 3). All EMA questions generally correlated with each other at all time blocks $(\rho=.335-.794, P=.001)$, except mood and perceived thinking abilities with fatigue and sleepiness or drowsiness at the evening time block (Table 3).

\section{Model of Actigraphy and Ecological Momentary Assessment Data \\ Relationships Between Actigraph and Ecological Momentary Assessment Data}

Spearman correlations (Table 4) revealed that greater WASO and poorer SE were related to EMA reports of greater fatigue (WASO: $\rho=.395, P=.005$; SE: $\rho=-.402, P=.004$ ) and greater sleepiness or drowsiness (WASO: $\rho=.381, P=.01$; SE: $\rho=-.404$, $P=.004)$ at the morning EMA time block the following day. In addition, longer SOL from the previous night correlated significantly with greater fatigue at the afternoon time block $(\rho=.372, P=.01)$. None of the other sleep variables from the previous night correlated significantly with any of the EMA questions at midday ( $\rho=-.358$ to.347, $P=.002-.003)$ or evening time blocks ( $\rho=-.292$ to.239, $P=.008-.009$ ) the following day.

\section{Ordinal Logistic Regression Analyses}

\section{Sleep Predicting Ecological Momentary Assessment Report of Mood}

The model did not indicate adequate fit for the morning (LR $\left.\chi_{3}^{2}=3.68, P=.30\right)$, midday $\left(\mathrm{LR} \chi_{3}^{2}=2.37, P=.50\right)$, afternoon (LR $\left.\chi_{3}^{2}=6.14, P=.11\right)$, or evening $\left(\operatorname{LR} \chi_{3}^{2}=2.77, P=.43\right)$ time blocks when predicting mood. None of the sleep measures emerged as significant predictors of EMA reports of mood at any of the 4 time blocks the following day $(z=0.24-0.74, P>.05)$.

\section{Sleep Predicting Ecological Momentary Assessment Report of Fatigue}

When predicting fatigue the next morning (Time 1), the model showed adequate fit $\left(\operatorname{LR} \chi_{3}^{2}=8.05, P=.04\right)$. Regression coefficients for sleep predictors indicated that decreased SE (odds ratio, OR, 1.16, 95\% CI 1.08-1.28) predicted an increase in fatigue in the morning time block, but WASO (OR 1.07, 95\% CI 0.96-1.14) and SOL (OR 1.01, 95\% CI 0.98-1.04) did not (Table 5).

When previous night's sleep measures were used to predict fatigue at midday the following day, the model demonstrated adequate fit ( $\left.\mathrm{LR} \chi_{3}^{2}=11.49, P=.004\right)$. Evaluation of regression coefficients indicated that an increase in SE (OR 1.12, 95\% CI 0.73-1.20) predicted a decrease in the EMA-based report of fatigue. Furthermore, WASO (OR 1.05, 95\% CI 0.97-1.11) and SOL (OR 1.00, 95\% CI 0.97-1.03) did not predict significant changes in EMA-based report of fatigue. 
Table 2. Participant averages of actigraph variables and correlations with participants' age.

\begin{tabular}{llcc}
\hline Actigraph & Mean (SD) & Pearson's $r$ & \multicolumn{2}{c}{$P$ value } \\
\hline Sleep onset latency (min) & $20.33(16.23)$ & $-.361^{\mathrm{a}}$ & .002 \\
Sleep efficiency (\%) & $91.93(5.02)$ & .202 & .08 \\
Wake after sleep onset (min) & $38.18(28.34)$ & -.193 & .10 \\
\hline
\end{tabular}

${ }^{\text {a }}$ Significant at $P<.01$.

Figure 1. Mean values of ecological momentary assessment variables across times 1-4.

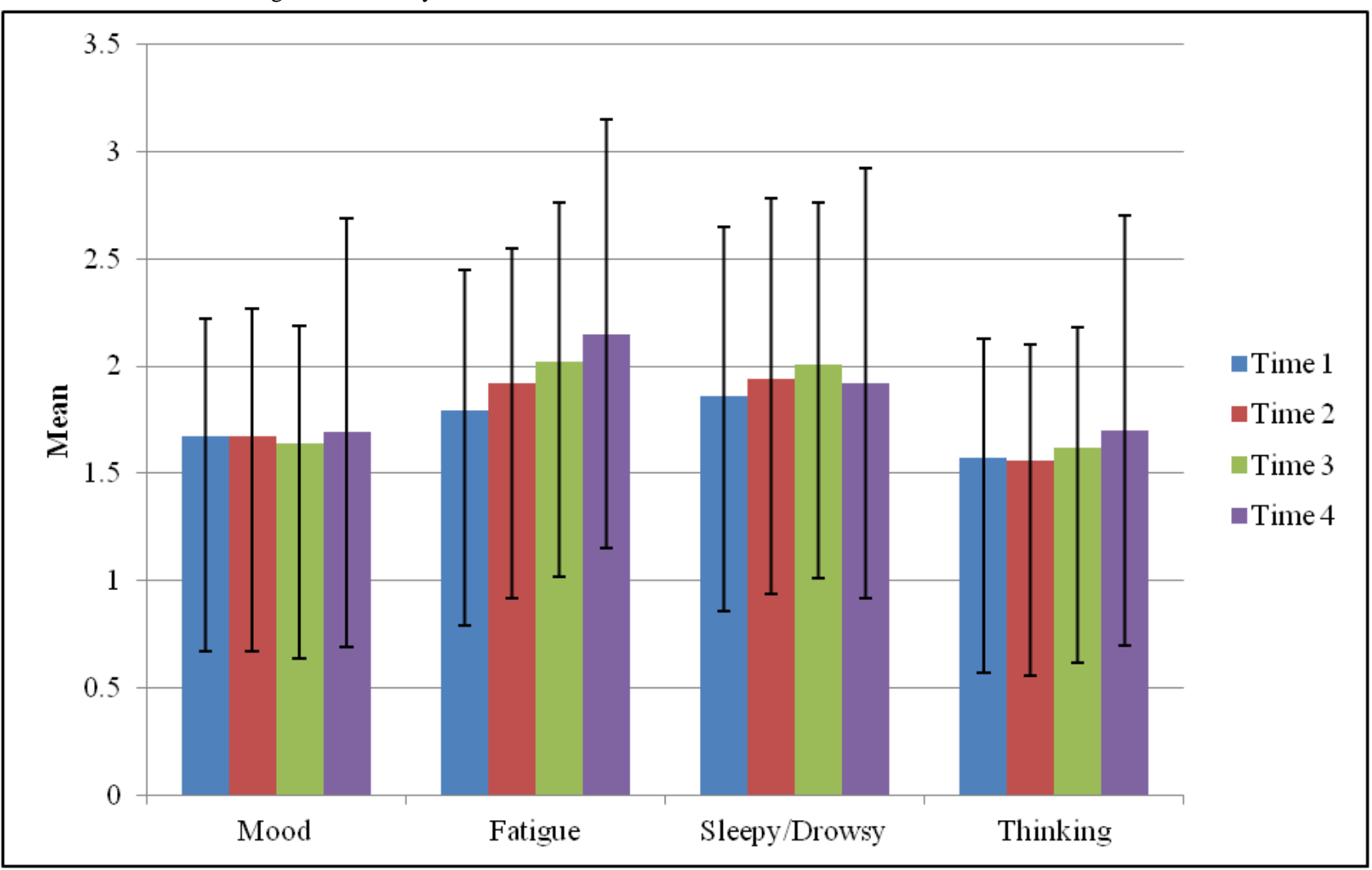

The models of actigraph sleep parameters did not indicate adequate fit for predicting EMA reports of fatigue in the afternoon $\left(\operatorname{LR} \chi_{3}^{2}=5.85, P=.12\right.$ ) or evening $\left(\operatorname{LR} \chi_{3}^{2}=2.28\right.$, $P=$.52). Sleep parameters from the previous night did not predict changes in EMA reports of fatigue the following afternoon or evening $(z=-0.62$ to $0.29, P>.05)$.

\section{Sleep Predicting Ecological Momentary Assessment Report of Sleepiness or Drowsiness}

When SOL, WASO, and SE from the previous night were used as predictors of EMA report of sleepiness or drowsiness the next morning, the ordinal logistic regression model showed adequate fit ( $\mathrm{LR} \chi_{3}^{2}=15.06, P=.002$ ). Regression coefficients indicated that increased $S E$ predicted a decrease in the EMA-based report of sleepiness or drowsiness the following morning (OR 0.87, 95\% CI 0.63-1.06). However, WASO (OR $0.99,95 \%$ CI $0.94-1.04$ ) and SOL (OR 1.02, 95\% CI 0.98-1.04) did not predict significant changes in EMA-based report of sleepiness or drowsiness.
Furthermore, models of sleep variables predicting EMA reports of sleepiness or drowsiness did not indicate adequate fit for midday $\left(\operatorname{LR} \chi_{3}^{2}=6.59, P=.09\right)$, afternoon $\left(\operatorname{LR} \chi_{3}^{2}=3.94, P=.27\right)$, or evening ( $\mathrm{LR} \chi_{3}{ }_{3}=5.70, P=.13$ ) time blocks. As such, sleep parameters from the previous night did not predict changes in EMA reports of sleepiness or drowsiness at midday, afternoon, or evening time blocks the following day $(z=-1.22$ to -0.09 , $P>$.05).

\section{Sleep Predicting Ecological Momentary Assessment Report of Perceived Thinking Abilities}

When SOL, WASO, and SE from the previous night were used as predictors of EMA report of perceived thinking abilities the next morning, the ordinal logistic regression models did not demonstrate adequate fit for any of the EMA time blocks, including morning $\left(\mathrm{LR} \chi_{3}^{2}=5.80, P=.12\right)$, midday $\left(\operatorname{LR} \chi_{3}^{2}=1.70\right.$, $P=.64$ ), afternoon (LR $\chi_{3}^{2}=0.27, P=.96$ ), or evening (LR $\left.\chi_{3}^{2}=0.97, P=.81\right)$. As such, none of the sleep parameters emerged as significant predictors of EMA reports of perceived thinking abilities the following day ( $z=-1.73$ to $0.26, P>.05)$. 
Table 3. Spearman correlations between previous night and ecological momentary assessment questions the following morning, midday, afternoon, and evening.

\begin{tabular}{|c|c|c|c|c|}
\hline \multirow[t]{2}{*}{ Day B } & \multicolumn{4}{|c|}{ Day A, Evening } \\
\hline & Mood & Fatigue & Sleepy or drowsy & Perceived thinking abilities \\
\hline \multicolumn{5}{|l|}{ Morning } \\
\hline Mood & $.747^{\mathrm{a}}$ & $.541^{\mathrm{a}}$ & $.419^{\mathrm{a}}$ & $.794^{\mathrm{a}}$ \\
\hline Fatigue & $.535^{\mathrm{a}}$ & $.579^{\mathrm{a}}$ & $.335^{\mathrm{a}}$ & $.465^{\mathrm{a}}$ \\
\hline Sleepy or drowsy & $.426^{\mathrm{a}}$ & $.507^{\mathrm{a}}$ & $.389^{\mathrm{a}}$ & $.417^{\mathrm{a}}$ \\
\hline Perceived thinking abilities & $.610^{\mathrm{a}}$ & $.479^{\mathrm{a}}$ & $.386^{\mathrm{a}}$ & $.674^{\mathrm{a}}$ \\
\hline \multicolumn{5}{|l|}{ Midday } \\
\hline Mood & $.777^{\mathrm{a}}$ & $.507^{\mathrm{a}}$ & $.358^{\mathrm{a}}$ & $.726^{\mathrm{a}}$ \\
\hline Fatigue & $.458^{\mathrm{a}}$ & $.655^{\mathrm{a}}$ & $.383^{\mathrm{a}}$ & $.426^{\mathrm{a}}$ \\
\hline Sleepy or drowsy & $.374^{\mathrm{a}}$ & $.529^{\mathrm{a}}$ & $.478^{\mathrm{a}}$ & $.393^{\mathrm{a}}$ \\
\hline Perceived thinking abilities & $.606^{\mathrm{a}}$ & $.506^{\mathrm{a}}$ & $.353^{\mathrm{a}}$ & $.655^{\mathrm{a}}$ \\
\hline \multicolumn{5}{|l|}{ Afternoon } \\
\hline Mood & $.675^{\mathrm{a}}$ & $.591^{\mathrm{a}}$ & $.451^{\mathrm{a}}$ & $.675^{\mathrm{a}}$ \\
\hline Fatigue & $.636^{\mathrm{a}}$ & $.720^{\mathrm{a}}$ & $.453^{\mathrm{a}}$ & $.571^{\mathrm{a}}$ \\
\hline Sleepy or drowsy & $.453^{\mathrm{a}}$ & $.409^{\mathrm{a}}$ & $.562^{\mathrm{a}}$ & $.419^{\mathrm{a}}$ \\
\hline Perceived thinking abilities & $.711^{\mathrm{a}}$ & $.554^{\mathrm{a}}$ & $.437^{\mathrm{a}}$ & $.771^{\mathrm{a}}$ \\
\hline \multicolumn{5}{|l|}{ Evening } \\
\hline Mood & $.474^{\mathrm{a}}$ & $.437^{\mathrm{a}}$ & $.430^{\mathrm{a}}$ & $.648^{\mathrm{a}}$ \\
\hline Fatigue & .284 & $.531^{\mathrm{a}}$ & $.571^{\mathrm{a}}$ & .305 \\
\hline Sleepy or drowsy & .197 & .218 & $.560^{\mathrm{a}}$ & .194 \\
\hline Perceived thinking abilities & $.383^{\mathrm{a}}$ & $.420^{\mathrm{a}}$ & .359 & $.517^{\mathrm{a}}$ \\
\hline
\end{tabular}

${ }^{\mathrm{a}}$ Significant correlation at $P<.01$. 
Table 4. Spearman correlations of ecological momentary assessment variables with previous night's sleep data.

\begin{tabular}{|c|c|c|c|}
\hline Ecological momentary assessment (next day) & Sleep onset latency (min) & Sleep efficiency $(\%)$ & Wake after sleep onset (min) \\
\hline \multicolumn{4}{|l|}{ Morning (Time 1) } \\
\hline Mood & .208 & -.287 & .284 \\
\hline Fatigue & .258 & -.402 & $.395^{\mathrm{a}}$ \\
\hline Sleepy or drowsy & .273 & $-.404^{\mathrm{a}}$ & $.381^{\mathrm{a}}$ \\
\hline Perceived thinking abilities & .174 & -.327 & .304 \\
\hline \multicolumn{4}{|l|}{ Midday (Time 2) } \\
\hline Mood & .262 & -.144 & .096 \\
\hline Fatigue & .328 & -.358 & .347 \\
\hline Sleepy or drowsy & .257 & -.316 & .267 \\
\hline Perceived thinking abilities & .312 & -.232 & .166 \\
\hline \multicolumn{4}{|l|}{ Afternoon (Time 3) } \\
\hline Mood & .204 & -.227 & .192 \\
\hline Fatigue & $.372^{\mathrm{a}}$ & -.329 & .287 \\
\hline Sleepy or drowsy & .208 & -.228 & .163 \\
\hline Perceived thinking abilities & .255 & -.153 & .041 \\
\hline \multicolumn{4}{|l|}{ Evening (Time 4) } \\
\hline Mood & .197 & -.262 & .165 \\
\hline Fatigue & .229 & -.273 & .225 \\
\hline Sleepy or drowsy & .145 & -.292 & .239 \\
\hline Perceived thinking abilities & .229 & -.133 & .054 \\
\hline
\end{tabular}

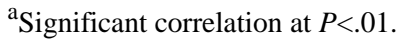


Table 5. Ordinal logistic regression odds ratios for models predicting ecological momentary assessment self-reports based on sleep variables obtained the previous night.

\begin{tabular}{|c|c|c|c|c|c|}
\hline \multirow[t]{2}{*}{ Ecological momentary assessment (next day) } & \multicolumn{3}{|c|}{ Actigraph data (Previous night) } & \multirow[t]{2}{*}{$\chi^{2}$} & \multirow[t]{2}{*}{$P$ value } \\
\hline & Sleep efficiency & Sleep onset latency & Wake after sleep onset & & \\
\hline \multicolumn{6}{|l|}{ Morning (Time 1) } \\
\hline Mood & 1.02 & 1.02 & 1.04 & 3.68 & .30 \\
\hline Fatigue & 1.16 & 1.01 & 1.07 & $8.05^{\mathrm{a}}$ & .04 \\
\hline Sleepy or drowsy & 0.87 & 1.02 & 0.99 & $15.06^{\mathrm{a}}$ & .002 \\
\hline Perceived thinking abilities & 0.87 & 1.03 & 0.99 & 2.80 & .12 \\
\hline \multicolumn{6}{|l|}{ Midday (Time 2) } \\
\hline Mood & 1.11 & 1.00 & 1.05 & 2.37 & .50 \\
\hline Fatigue & 1.12 & 1.00 & 1.05 & $11.49^{\mathrm{a}}$ & .01 \\
\hline Sleepy or drowsy & 1.00 & 1.01 & 1.02 & 6.59 & .09 \\
\hline Perceived thinking abilities & 0.99 & 1.01 & 1.02 & 1.70 & .63 \\
\hline \multicolumn{6}{|l|}{ Afternoon (Time 3) } \\
\hline Mood & 1.05 & 0.99 & 1.04 & 6.14 & .11 \\
\hline Fatigue & 0.93 & 1.01 & 1.02 & 5.85 & .12 \\
\hline Sleepy or drowsy & 0.86 & 1.00 & 0.99 & 3.94 & .27 \\
\hline Perceived thinking abilities & 0.84 & 1.00 & 0.99 & .27 & .97 \\
\hline \multicolumn{6}{|l|}{ Evening (Time 4) } \\
\hline Mood & 1.01 & 1.00 & 1.02 & 2.77 & .42 \\
\hline Fatigue & 1.20 & 1.00 & 1.04 & 2.28 & .52 \\
\hline Sleepy or drowsy & 1.01 & 1.00 & 1.01 & 5.70 & .13 \\
\hline Perceived thinking abilities & 0.97 & 1.00 & 0.99 & .97 & .81 \\
\hline
\end{tabular}

${ }^{a}$ Significant at $P<.05$. Confidence intervals are reported in-text.

\section{Discussion}

\section{Principal Findings}

This study was an exploratory approach to examine relationships between objectively measured sleep quality (eg, WASO, SOL, and SE) and self-report of mood, fatigue, sleepiness or drowsiness, and perceived thinking abilities in a cognitively healthy older adult sample using actigraphy and EMA phone-based self-reports.

Older age was related to EMA reports of greater sleepiness or drowsiness and negative mood in the morning. Relationships between participants' age and EMA questions of fatigue and perceived thinking abilities did not achieve significance. When the EMA data were compared between the previous night and the following day, reports of fatigue were markedly lower in the morning; however, EMA reports of sleepiness or drowsiness remained stable from the evening to morning and midday time blocks the following day. It is possible that the EMA questions of fatigue and sleepiness or drowsiness are not measuring identical constructs and that the wording of these 2 questions affected the reporting by participants (ie, "current" vs "past 2 hours").
Consistent with the initial hypotheses, EMA reports of fatigue and sleepiness or drowsiness were related to previous night's sleep. Specifically, poorer SE was related to greater sleepiness or drowsiness the next morning. However, WASO and SOL were not significant predictors of EMA measures of sleepiness or drowsiness and fatigue the following morning. Furthermore, the TST was removed from the regression analyses owing to a limited relationship with any of the dependent measures, and no evidence of contributing to the overall model. Sleep measures were not strongly related to mood and perceived thinking abilities; this relationship was likely affected by the minimal variation in the EMA data for these questions (ie, mostly average reports).

Findings of predictive relationships between sleep the previous night and EMA measures the next morning were inconsistent. Poorer SE was associated with increased levels of sleepiness or drowsiness at the morning time block and levels of fatigue at the morning and midday time blocks. These findings support the research of McCrae et al [17] who found relationships between greater self-reported sleep problems with subjective complaints of daytime fatigue in older adults. This study expands these findings to include an objective assessment of sleep (actigraphy) as predictors of subjective daytime fatigue. 
Previous night's sleep predicted only morning or midday EMA reports but did not predict EMA reports of fatigue and sleepiness or drowsiness at afternoon and evening time blocks. Other daytime factors (eg, naps and consumption of caffeine) may mitigate the impact of the previous night's sleep on energy levels later in the day. For example, one study found that greater variability in daytime naps was associated with poorer health status [37], and it is recommended that future research consider the implication of naps on cognitive and functional abilities.

Previous night's sleep did not predict EMA reports of mood and perceived thinking abilities the next day. Although the literature suggests that self-reported poor sleep is associated with depression and decreased functional status [38], this study found that objective sleep was not directly associated with mood. Our findings support the research of previous studies [30] that subjective, but not objective, sleep quality was associated with self-reported affect (eg, poorer sleep quality correlated with more negative affect). Of note, participants in this study were screened for depressive symptoms at the outset; thus, relationships with mood may be affected by the baseline levels of emotional symptoms for the participants. Interestingly, our results contrast the findings of Russell et al [31] who found that subjective but not objective sleep measures predicted self-reported fatigue the following morning, as our objective sleep measures did predict reports of next-morning fatigue; however, this study was in a generally healthy older adult sample, whereas others evaluated patients with chronic fatigue syndrome [31], suggesting differences in detections within clinical populations.

\section{Limitations}

The study sample was predominantly female, highly educated, and racially homogenous, which may limit the generalization of findings to other demographic groups. The number of participants excluded from the initial sample was substantial as a result of study requirements; larger sample sizes, as well as comparisons of healthy groups to those with sleep disorders or sleep medications, would be useful to assess the influence of medical and pharmaceutical impact on sleep and daily functioning. By nature of the EMA data, there were many individual variables and, as a result, a large number of analyses were conducted in this study, increasing the possibility of false-positive findings. To compensate for this, we used more stringent $P$ values and reduced variables in the models to only those identified in initial correlation analyses (ie, removal of actigraphic TST and EMA daily activity performance). Regarding EMA limitations, the type of telephone number (eg, home vs cell phone) may have influenced the data collection, such that individuals who provided home phone numbers may not have been home to respond to the phone calls; the qualitative nature of missed response items is worthy of further investigation. In addition, the time blocks chosen for this study were based on focus-group information; however, this may not have accurately captured variation in wake-up time (ie, participants who would normally wake up sooner or later than the phone call period). Sensor-based assessment, such as using actigraphy or wrist-based fitness devices, could be a way to prompt EMA questions within a designated time of waking up, thus adjusting to the individual chronology of participants.

\section{Future Directions}

Future research should consider longitudinal effects of sleep and perceived functioning on actual cognitive and everyday performance. For example, if maintaining consistent sleep patterns is found to be more predictive of perceived functioning and, thus, contributing to actual cognitive performance, this could inform treatments for sleep disruption. Given the prevalence of naps as individuals age [39], it would be beneficial to include the influence of napping in models of sleep and daily functioning (eg, pre- and postnap EMA reports). Furthermore, research on sleep and neurodegenerative disease has explored the sleep profiles of those with mild cognitive impairment [40,41] and dementia [42], as well as neurological changes in poor sleepers with cognitive deficits [43]. Additional research efforts should investigate whether poor sleep is a robust contributor or risk factor for cognitive decline, as monitoring changes in sleep could be beneficial for the treatment of neurodegenerative disease.

\section{Acknowledgments}

This study was partially supported by the National Institutes of Health National Institute of Biomedical Imaging and Bioengineering under Grant \#R01 EB009675, and by the National Science Foundation under Grant \#DGE-0900781.

\section{Conflicts of Interest}

None declared.

\section{References}

1. Song Y, Blackwell T, Yaffe K, Ancoli-Israel S, Redline S, Stone KL, Osteoporotic Fractures in Men (MrOS) Study Group. Relationships between sleep stages and changes in cognitive function in older men: the MrOS Sleep Study. Sleep 2015 Mar 01;38(3):411-421 [FREE Full text] [doi: 10.5665/sleep.4500] [Medline: 25325465]

2. Middelkoop HA, Smilde-van den Doel DA, Neven AK, Kamphuisen HA, Springer CP. Subjective sleep characteristics of 1,485 males and females aged 50-93: effects of sex and age, and factors related to self-evaluated quality of sleep. J Gerontol A Biol Sci Med Sci 1996 May;51(3):M108-M115. [Medline: $\underline{8630703}$ ]

3. Foley DJ, Monjan AA, Brown SL, Simonsick EM, Wallace RB, Blazer DG. Sleep complaints among elderly persons: an epidemiologic study of three communities. Sleep 1995 Jul;18(6):425-432. [Medline: 7481413] 
4. Ohayon MM. Epidemiology of insomnia: what we know and what we still need to learn. Sleep Med Rev 2002 Apr;6(2):97-111. [Medline: $\underline{12531146]}$

5. Parsey CM, Schmitter-Edgecombe M, Belenky G. Sleep and everyday functioning in older adulthood. J Appl Gerontol 2015 Feb;34(1):48-72. [doi: 10.1177/0733464812458364] [Medline: 25548088]

6. Driscoll HC, Serody L, Patrick S, Maurer J, Bensasi S, Houck PR, et al. Sleeping well, aging well: a descriptive and cross-sectional study of sleep in "successful agers" 75 and older. Am J Geriatr Psychiatry 2008 Jan;16(1):74-82 [FREE Full text] [doi: 10.1097/JGP.0b013e3181557b69] [Medline: 18070833]

7. Vance DE, Heaton K, Eaves Y, Fazeli PL. Sleep and cognition on everyday functioning in older adults: implications for nursing practice and research. J Neurosci Nurs 2011 Oct;43(5):261-71; quiz 272. [doi: 10.1097/JNN.0b013e318227efb2] [Medline: 21926521]

8. Rowe JW, Kahn RL. Successful aging. Gerontologist 1997 Aug;37(4):433-440. [Medline: 9279031]

9. Kang S, Yoon I, Lee SD, Kim T, Lee CS, Han JW, et al. Subjective memory complaints in an elderly population with poor sleep quality. Aging Ment Health 2017 May;21(5):532-536. [doi: 10.1080/13607863.2015.1124839] [Medline: 26689628]

10. Waller KL, Mortensen EL, Avlund K, Osler M, Fagerlund B, Lauritzen M, et al. Subjective sleep quality and daytime sleepiness in late midlife and their association with age-related changes in cognition. Sleep Med 2016 Jan;17:165-173. [doi: 10.1016/j.sleep.2015.01.004] [Medline: 26188599]

11. Belleville S, Fouquet C, Duchesne S, Collins DL, Hudon C. Detecting early preclinical Alzheimer's disease via cognition, neuropsychiatry, and neuroimaging: qualitative review and recommendations for testing. J Alzheimers Dis 2014;42 Suppl 4:S375-S382. [doi: 10.3233/JAD-141470] [Medline: 25190629]

12. Cricco M, Simonsick EM, Foley DJ. The impact of insomnia on cognitive functioning in older adults. J Am Geriatr Soc 2001 Sep;49(9):1185-1189. [Medline: 11559377]

13. Jelicic M, Bosma H, Ponds RW, Van Boxtel MP, Houx PJ, Jolles J. Subjective sleep problems in later life as predictors of cognitive decline. Report from the Maastricht Ageing Study (MAAS). Int J Geriatr Psychiatry 2002 Jan;17(1):73-77.

[Medline: 11802234]

14. Marshall L, Born J. The contribution of sleep to hippocampus-dependent memory consolidation. Trends Cogn Sci 2007 Oct;11(10):442-450. [doi: 10.1016/j.tics.2007.09.001] [Medline: 17905642]

15. Walker MP, Stickgold R. Sleep, memory, and plasticity. Annu Rev Psychol 2006;57:139-166. [doi: 10.1146/annurev.psych.56.091103.070307] [Medline: 16318592]

16. Stavitsky K, Neargarder S, Bogdanova Y, McNamara P, Cronin-Golomb A. The impact of sleep quality on cognitive functioning in Parkinson's disease. J Int Neuropsychol Soc 2012 Jan;18(1):108-117 [FREE Full text] [doi: 10.1017/S1355617711001482] [Medline: 22152279]

17. McCrae CS, Rowe MA, Tierney CG, Dautovich ND, Definis AL, McNamara JPH. Sleep complaints, subjective and objective sleep patterns, health, psychological adjustment, and daytime functioning in community-dwelling older adults. J Gerontol B Psychol Sci Soc Sci 2005 Jul;60(4):P182-P189. [Medline: 15980285]

18. Endeshaw YW, Yoo W. Association Between Social and Physical Activities and Insomnia Symptoms Among Community-Dwelling Older Adults. J Aging Health 2016 Sep;28(6):1073-1089 [FREE Full text] [doi: 10.1177/0898264315618921] [Medline: 26690253]

19. Smyth JM, Smyth JM. Ecological Momentary Assessment Research in Behavioral medicine. Journal of Happiness Studies 2003;4(1):35-52. [doi: 10.1023/A:1023657221954]

20. Stone AA, Shiffman S. Ecological momentary assessment (EMA) in behavioral medicine. Annals of Behavioral Medicine 1994;16:199-202. [doi: 10.1093/abm/16.3.199]

21. Dzierzewski JM, Buman MP, Giacobbi PR, Roberts BL, Aiken-Morgan AT, Marsiske M, et al. Exercise and sleep in community-dwelling older adults: evidence for a reciprocal relationship. J Sleep Res 2014 Feb;23(1):61-68 [FREE Full text] [doi: 10.1111/jsr.12078] [Medline: 23980920]

22. Marszalek J, Morgulec-Adamowicz N, Rutkowska I, Kosmol A. Using ecological momentary assessment to evaluate current physical activity. Biomed Res Int 2014;2014:915172 [FREE Full text] [doi: 10.1155/2014/915172] [Medline: 25126580]

23. Schwerdtfeger A, Eberhardt R, Chmitorz A, Schaller E. Momentary affect predicts bodily movement in daily life: an ambulatory monitoring study. J Sport Exerc Psychol 2010 Oct;32(5):674-693. [Medline: 20980710]

24. Wegner KE, Smyth JM, Crosby RD, Wittrock D, Wonderlich SA, Mitchell JE. An evaluation of the relationship between mood and binge eating in the natural environment using ecological momentary assessment. Int J Eat Disord 2002 Nov;32(3):352-361. [doi: 10.1002/eat.10086] [Medline: 12210650]

25. Kim J, Kikuchi H, Yamamoto Y. Systematic comparison between ecological momentary assessment and day reconstruction method for fatigue and mood states in healthy adults. Br J Health Psychol 2013 Feb;18(1):155-167. [doi: 10.1111/bjhp.12000] [Medline: 23017062]

26. Shiffman S, Stone AA, Hufford MR. Ecological momentary assessment. Annu Rev Clin Psychol 2008;4:1-32. [Medline: 18509902]

27. Jones M, Johnston D. Understanding phenomena in the real world: the case for real time data collection in health services research. J Health Serv Res Policy 2011 Jul;16(3):172-176. [doi: 10.1258/jhsrp.2010.010016] [Medline: 21543380] 
28. Kay DB, Dzierzewski JM, Rowe M, McCrae CS. Greater night-to-night variability in sleep discrepancy among older adults with a sleep complaint compared to noncomplaining older adults. Behav Sleep Med 2013 Apr;11(2):76-90. [doi: 10.1080/15402002.2011.602775] [Medline: 23137288]

29. Lemola S, Ledermann T, Friedman EM. Variability of sleep duration is related to subjective sleep quality and subjective well-being: an actigraphy study. PLoS One 2013;8(8):e71292 [FREE Full text] [doi: 10.1371/journal.pone.0071292] [Medline: 23967186]

30. McCrae CS, McNamara JPH, Rowe MA, Dzierzewski JM, Dirk J, Marsiske M, et al. Sleep and affect in older adults: using multilevel modeling to examine daily associations. J Sleep Res 2008 Mar;17(1):42-53 [FREE Full text] [doi: 10.1111/j.1365-2869.2008.00621.x] [Medline: 18275554$]$

31. Russell C, Wearden AJ, Fairclough G, Emsley RA, Kyle SD. Subjective but Not Actigraphy-Defined Sleep Predicts Next-Day Fatigue in Chronic Fatigue Syndrome: A Prospective Daily Diary Study. Sleep 2016 Apr 01;39(4):937-944 [FREE Full text] [doi: 10.5665/sleep.5658] [Medline: 26715232]

32. Brandt J, Spencer M, Folstein M. The telephone interview for cognitive status. Neuropsychiatry Neuropsychol Behav Neurol 1988;1:111-117.

33. Duara R, Loewenstein DA, Greig-Custo MT, Raj A, Barker W, Potter E, et al. Diagnosis and staging of mild cognitive impairment, using a modification of the clinical dementia rating scale: the mCDR. Int J Geriatr Psychiatry 2010 Mar;25(3):282-289 [FREE Full text] [doi: 10.1002/gps.2334] [Medline: 19565573]

34. Yesavage JA, Sheikh JI. 9/Geriatric Depression Scale (GDS). Clinical Gerontologist 2008 Oct 25;5(1-2):165-173. [doi: 10.1300/J018v05n01_09]

35. Jean-Louis G, Kripke DF, Mason WJ, Elliott JA, Youngstedt SD. Sleep estimation from wrist movement quantified by different actigraphic modalities. J Neurosci Methods 2001 Feb 15;105(2):185-191. [Medline: 11275275]

36. Miyata S, Noda A, Iwamoto K, Kawano N, Okuda M, Ozaki N. Poor sleep quality impairs cognitive performance in older adults. J Sleep Res 2013 Oct;22(5):535-541 [FREE Full text] [doi: 10.1111/jsr.12054] [Medline: 23560612]

37. Dautovich ND, Kay DB, Perlis ML, Dzierzewski JM, Rowe MA, McCrae CS. Day-to-day variability in nap duration predicts medical morbidity in older adults. Health Psychol 2012 Sep;31(5):671-676 [FREE Full text] [doi: 10.1037/a0027374] [Medline: 22369491]

38. Martin JL, Fiorentino L, Jouldjian S, Josephson KR, Alessi CA. Sleep quality in residents of assisted living facilities: effect on quality of life, functional status, and depression. J Am Geriatr Soc 2010 May;58(5):829-836 [FREE Full text] [doi: 10.1111/j.1532-5415.2010.02815.x] [Medline: 20722819]

39. Dautovich N, McCrae CS, Rowe M. Subjective and objective napping and sleep in older adults: are evening naps "bad" for nighttime sleep? J Am Geriatr Soc 2008 Sep;56(9):1681-1686 [FREE Full text] [doi: 10.1111/j.1532-5415.2008.01822.x] [Medline: 18691289 ]

40. Hayes TL, Riley T, Mattek N, Pavel M, Kaye JA. Sleep habits in mild cognitive impairment. Alzheimer Dis Assoc Disord 2014;28(2):145-150 [FREE Full text] [doi: 10.1097/WAD.0000000000000010] [Medline: 24145694]

41. Naismith SL, Rogers NL, Lewis SJG, Diamond K, Terpening Z, Norrie L, et al. Sleep disturbance in mild cognitive impairment: differential effects of current and remitted depression. Acta Neuropsychiatr 2011 Aug;23(4):167-172. [doi: 10.1111/j.1601-5215.2011.00555.x] [Medline: 25379794]

42. Merlino G, Piani A, Gigli GL, Cancelli I, Rinaldi A, Baroselli A, et al. Daytime sleepiness is associated with dementia and cognitive decline in older Italian adults: a population-based study. Sleep Med 2010 Apr;11(4):372-377. [doi: 10.1016/j.sleep.2009.07.018] [Medline: 20219426]

43. Gelber RP, Redline S, Ross GW, Petrovitch H, Sonnen JA, Zarow C, et al. Associations of brain lesions at autopsy with polysomnography features before death. Neurology 2015 Jan 20;84(3):296-303 [FREE Full text] [doi: 10.1212/WNL.0000000000001163] [Medline: 25503626]

\author{
Abbreviations \\ D-KEFS: Delis-Kaplan Executive Functioning System \\ EMA: ecological momentary assessment \\ LR: logistic regression \\ SE: sleep efficiency \\ SOL: sleep onset latency \\ TICS: telephone interview for cognitive status \\ TST: total sleep time \\ WASO: wake after sleep onset
}


Edited by J Wang; submitted 18.06.18; peer-reviewed by A Davoudi, R Falck; comments to author 07.10.18; revised version received 26.10.18; accepted 30.10.18; published 18.01.19

Please cite as:

Parsey CM, Schmitter-Edgecombe M

Using Actigraphy to Predict the Ecological Momentary Assessment of Mood, Fatigue, and Cognition in Older Adulthood: Mixed-Methods Study

JMIR Aging 2019;2(1):e11331

URL: http://aging.jmir.org/2019/1/e11331/

doi: $10.2196 / 11331$

PMID: 31518282

(C)Carolyn M Parsey, Maureen Schmitter-Edgecombe. Originally published in JMIR Aging (http://aging.jmir.org), 18.01.2019. This is an open-access article distributed under the terms of the Creative Commons Attribution License (https://creativecommons.org/licenses/by/4.0/), which permits unrestricted use, distribution, and reproduction in any medium, provided the original work, first published in JMIR Aging, is properly cited. The complete bibliographic information, a link to the original publication on http://aging.jmir.org, as well as this copyright and license information must be included. 